\title{
Memoria del movimiento (ensaio visual)
}

Edgar Calel (Guatemala) *

Com texto de Sebastián Eduardo [Dávila] (Guatemala; Alemanha) **

https://doi.org/10.22409/poiesis.v21i35.40414

Edgar Calel (1987) é um artista Maya kaqchikel da Guatemala. Sua prática artística, pautada pela mobilidade e pelo movimento, lida com temas ligados à migração, ao deslocamento e ao retorno. Originário de Comalapa, Calel saiu de sua cidade natal para estudar arte, fazendo de sua vida uma jornada. Neste ensaio visual são apresentados registros de algumas séries como Yo vivo en ti, Tú vives en mi; B'atz - tejido constelación de saberes; Ixim (Maíz); e Laberinto de los Pájaros. O ensaio se encerra com o texto Memoria del movimiento, de Sebastián Eduardo [Dávila].

\footnotetext{
* Edgar Calel é um pintor, performer e videasta guatemalteco. E-mail: edgarcalel387@gmail.com.

** Sebastián Eduardo [Dávila] estudou História das Ciências da Arte e do Cinema na Universidade Friedrich Schiller em Jena, Alemanha, na Universidade Autônoma Nacional do México na Cidade do México e na Freie Universität em Berlim. Atualmente, trabalha como mediador no Galerie Wedding e no KINDL - Zentrum für Zeitgenössische Kunst, em Berlim. E-mail: seduardodav@gmail.com
} 
Ficha técnica de imágenes de piezas de Edgar Calel

Yo vivo en ti - tú vives en mí, 2010.

intervención e instalación de documentos que certifican el lugar y fecha de nacimientos de personas originarias del pueblo kaqchikel

(Foto: Cortesía familia Calel Apén)

Serie Qa bäy -Qulef - Qa káslemal - Qetalh

Nuestros sustento - Nuestra tierra - Nuestra Vida - Nuestro Rastro, 2018.

performance

(Foto: Fabio Alkamino)

B'atz Constelación de Saberes, 2015.

fotografía, díptico

$61 \mathrm{~cm} \times 81 \mathrm{~cm} \mathrm{C/P}$

(Foto: Julio Calel)

Laberinto de los pájaros, 2008.

instalación (cajas de cartón pintadas en su interior con tinta óleo)

(Foto Julio Calel - Lisandro Calel)

CALEL, Edgar. Memoria del movimiento (com texto de Sebastián Eduardo Dávila).

Poiésis, Niterói, v. 21, n. 35, p. 163-176, jan./jun. 2020.

[https://doi.org/10.22409/poiesis.v21i35.40414] 

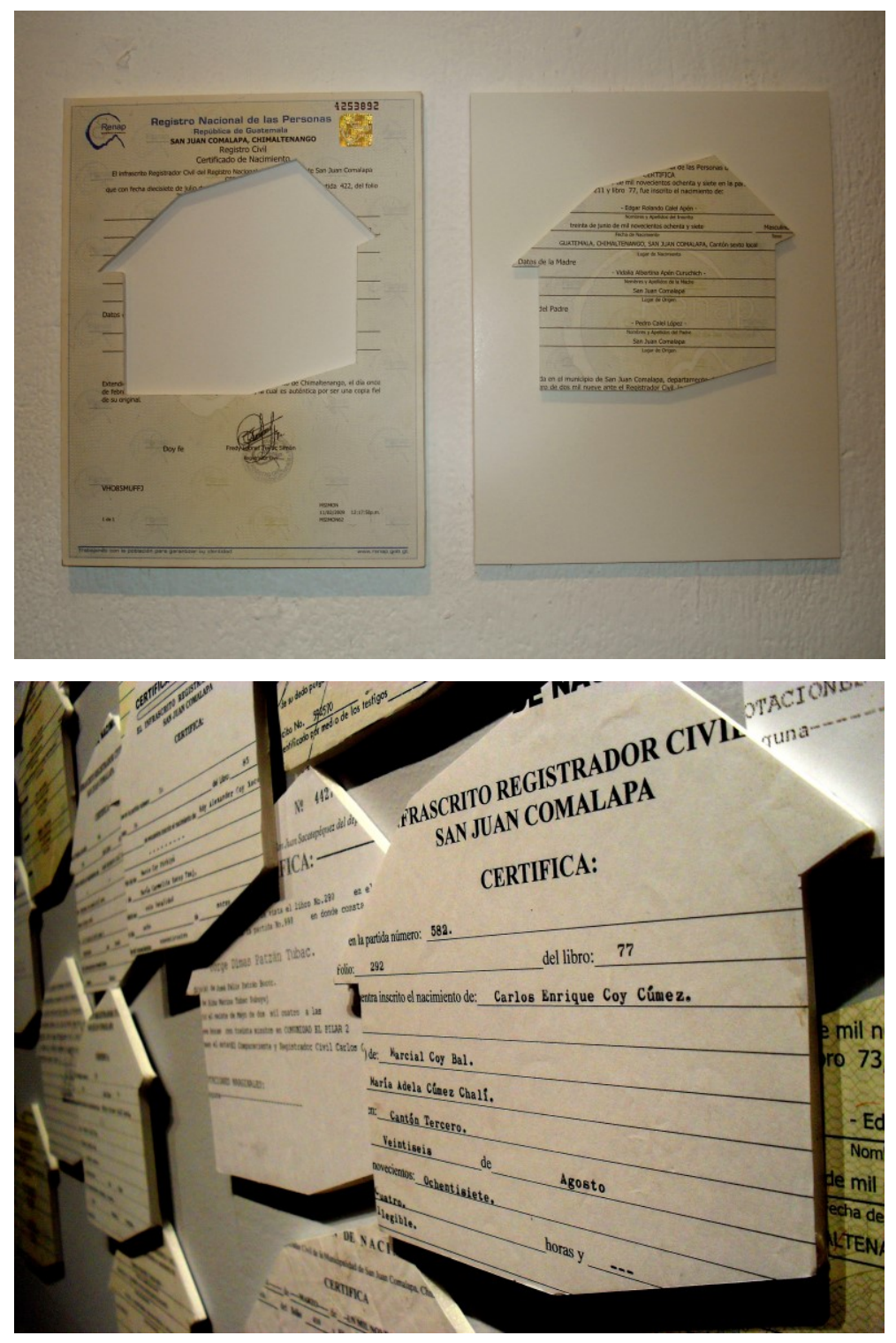

1, 2 - Yo vivo en ti - tú vives en mí, 2010.

intervención e instalación de documentos que certifican el lugar y fecha de nacimientos de personas originarias del pueblo kaqchikel

(Foto: Cortesía familia Calel Apén) 


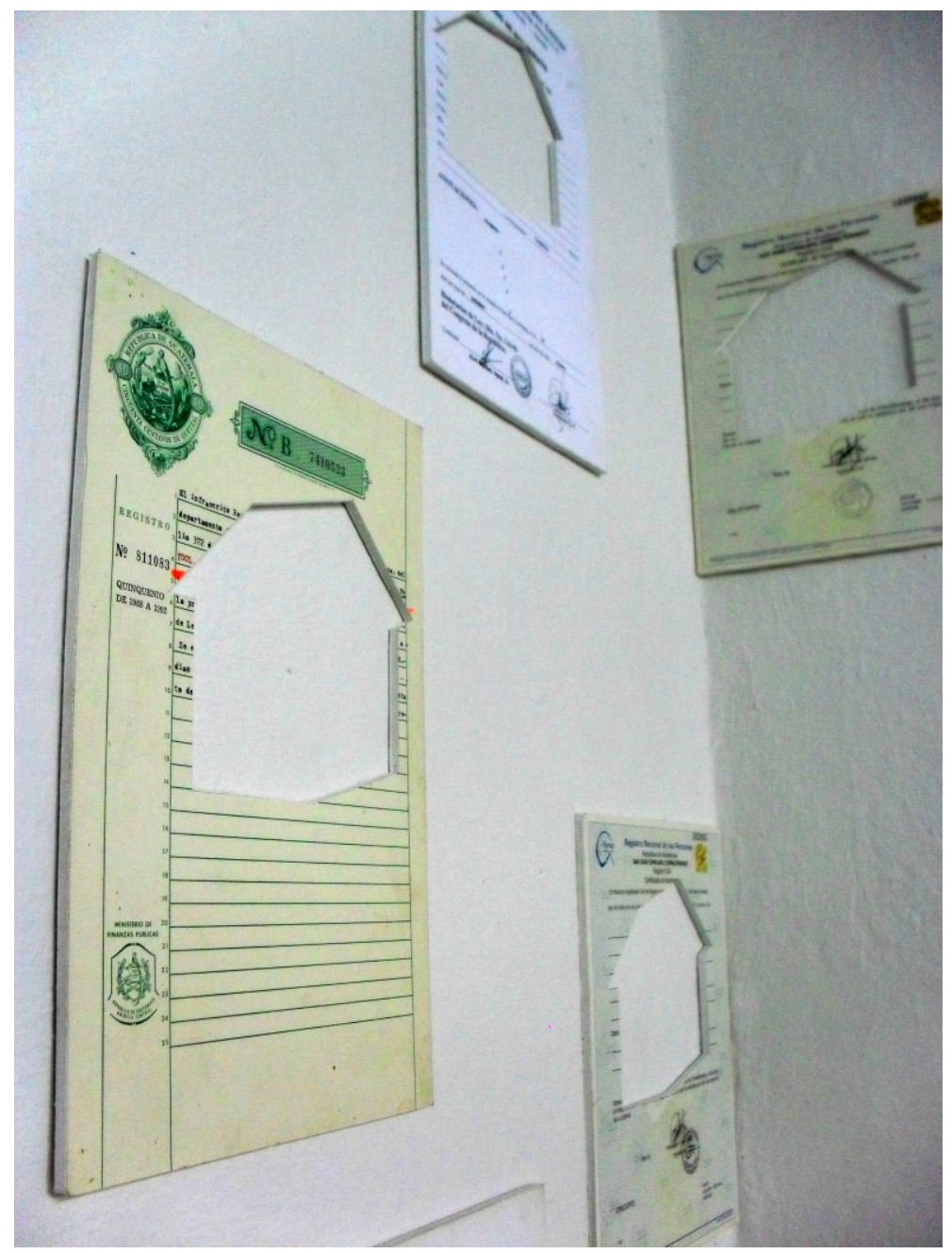

3 - Yo vivo en ti - tú vives en mí, 2010.

intervención e instalación de documentos que certifican el lugar y fecha de nacimientos de personas originarias del pueblo kaqchikel

(Foto: Cortesía familia Calel Apén) 


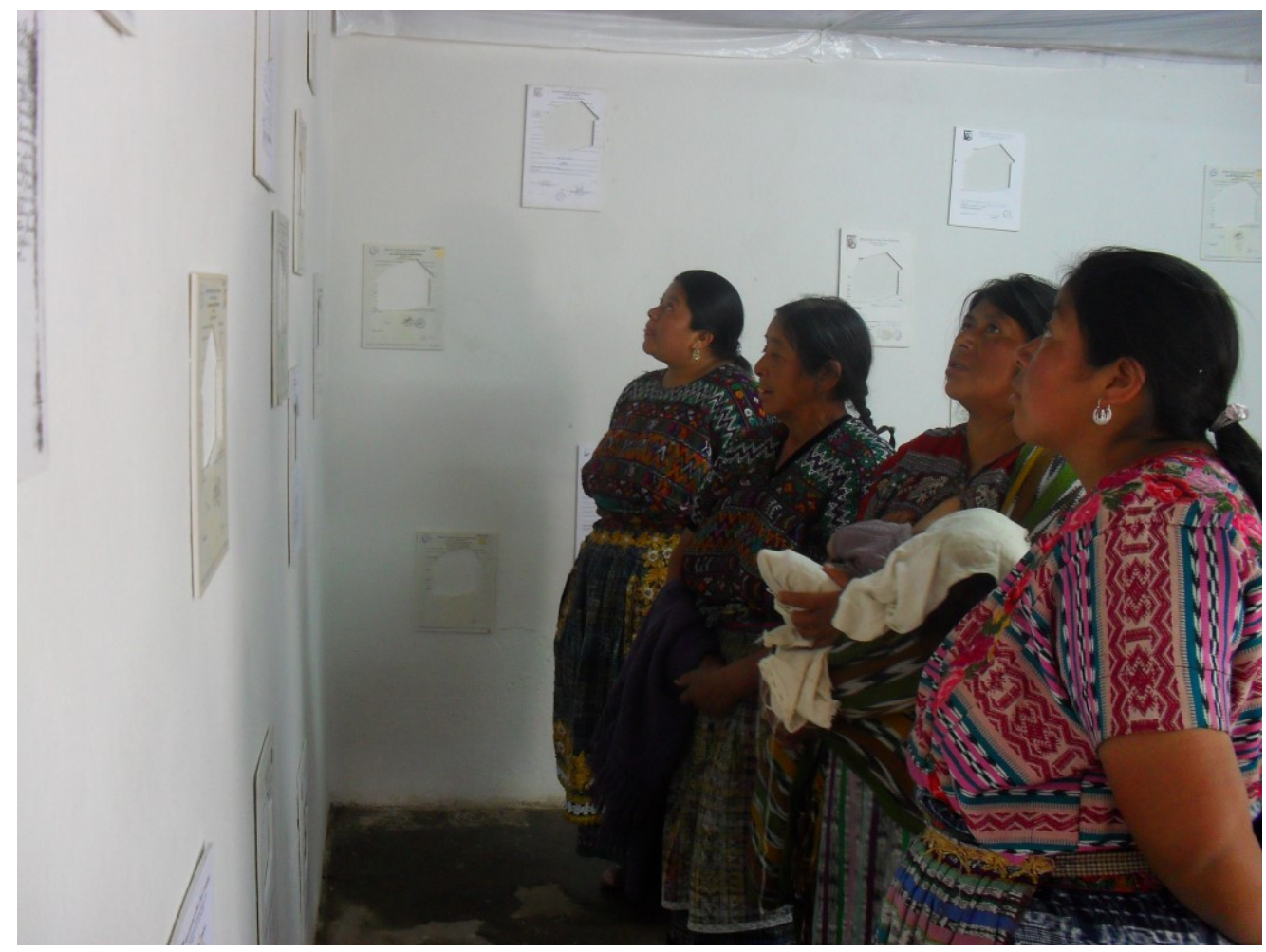

4 - Yo vivo en ti - tú vives en mí, 2010.

intervención e instalación de documentos que certifican el lugar y fecha de nacimientos de personas originarias del pueblo kaqchikel

(Foto: Cortesía familia Calel Apén) 

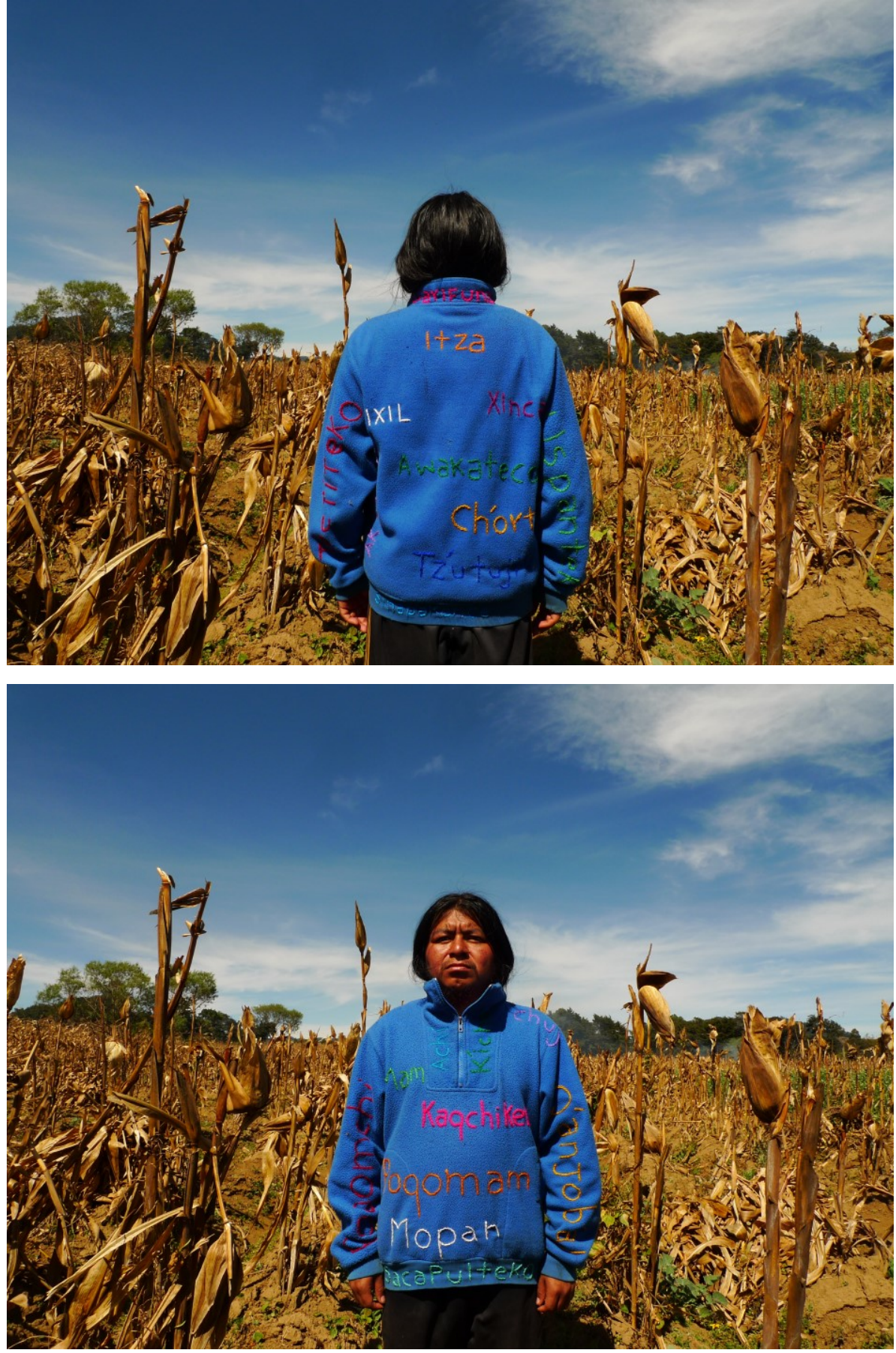

5, 6 - B'atz Constelación de Saberes, 2015. fotografía, díptico

$61 \mathrm{~cm} \times 81 \mathrm{~cm} \mathrm{C/P}$

(Foto: Julio Calel) 

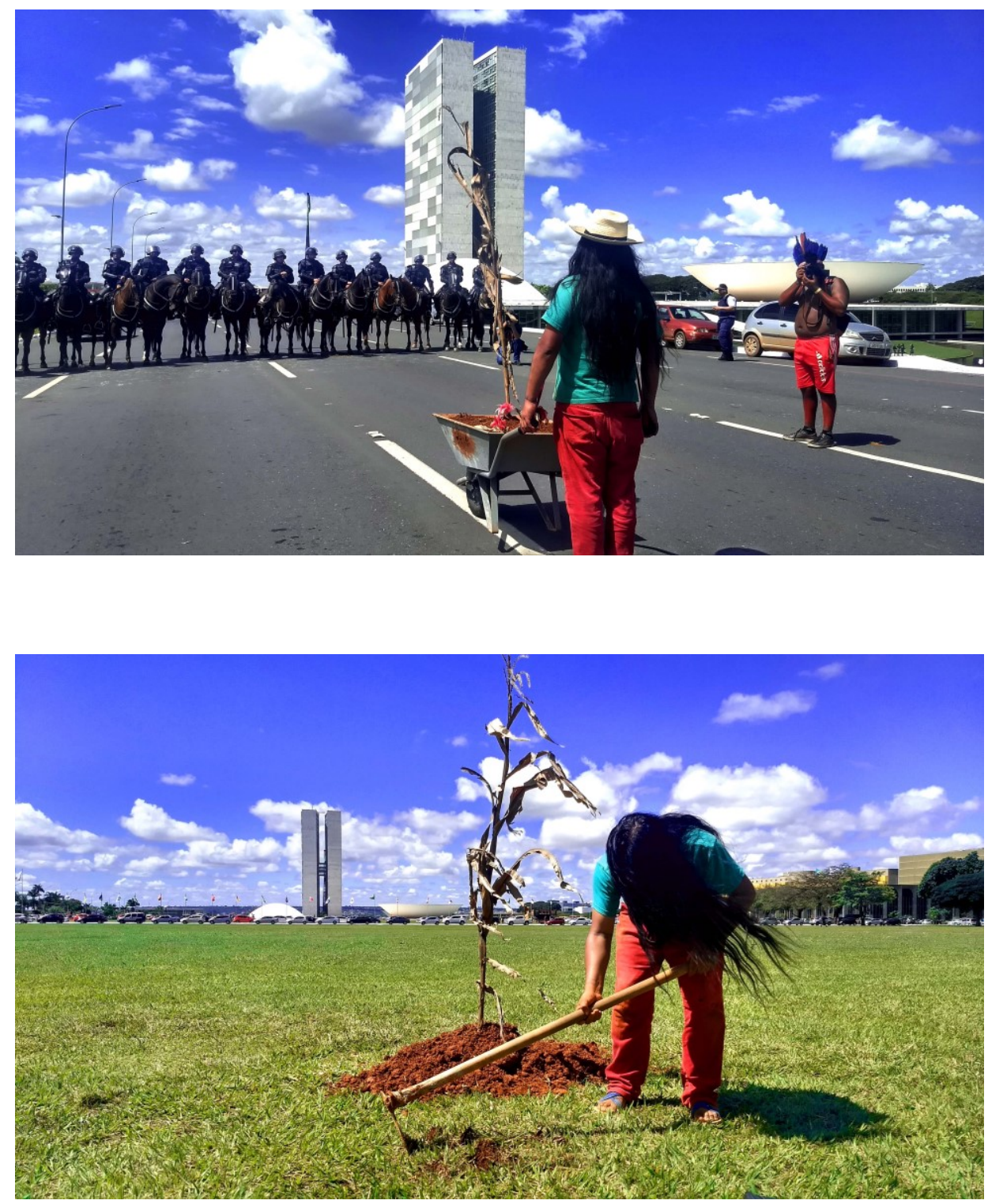

7, 8 e 9 (página seguinte) - Serie Qa bäy -Qulef - Oa káslemal - Oetalh

Nuestros sustento - Nuestra tierra - Nuestra Vida - Nuestro Rastro, 2018.

performance

(Foto: Fabio Alkamino) 


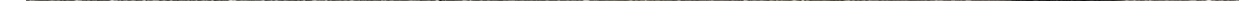




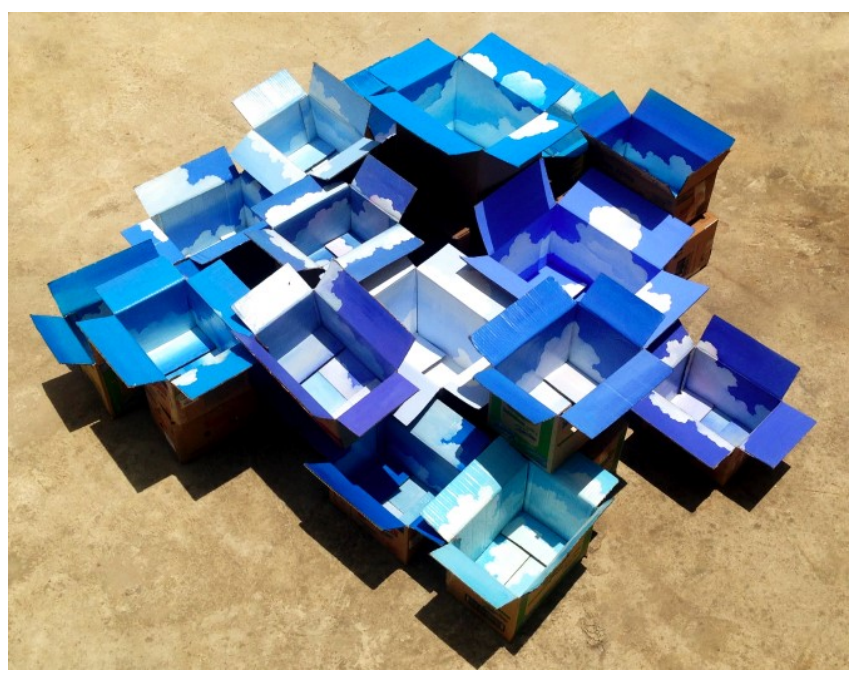

10 - Laberinto de los pájaros, 2008.

instalación (cajas de cartón pintadas en su interior con tinta óleo)

(Foto Julio Calel - Lisandro Calel) 
MEMORIA DEL MOVIMIENTO - por Sebastián Eduardo [Dávila]

\section{Los sueños en las alas de un pájaro de hierro.}

¿Qué parte de mí se queda cuando migro, qué se viene conmigo? Esta fotografía muestra un certificado de nacimiento, emitido en San Juan Comalapa (Guatemala), agujereado con la forma de una casa. La casa es el corazón del documento (en ella están escritos los datos personales del sujeto nacido) y está expuesta al lado del certificado restante, que forma su contorno. Se trata de un proceso de violencia ejercida sobre un papel que, en su función de documento oficial, da fe del nacimiento y la existencia de alguien, y no de cualquiera: de Edgar Rolando Calel Apén. Fue él mismo quien, en su función de artista, mutiló el certificado. Y no sólo eso: en otra variación de Yo vivo en ti, Tú vives en mí, mutiló también las partidas de nacimiento de amigxs y conocidxs comalapenses, para luego exponerlas separadas, en su casa particular en Comalapa (el contorno) y en un espacio de exposición en Ciudad de Guatemala (la casa). El sujeto migrado es uno fragmentado. Deja atrás algo que sólo quienes lo conocían pueden ver y se transforma según las nuevas relaciones, de poder y de afecto, que establece en los territorios de tránsito y destino.

El formato de la residencia artística implica una migración temporal: unx artista viaja a un nuevo territorio a vivir por algunos meses, durante los cuales comparte, desarrolla y expone su trabajo, dialogando permanentemente no sólo con artistas, críticxs y curadorxs, sino también con personas ajenas al circuito de arte pero íntimamente relacionadas al territorio y los lugares transitados. Una vez concluida su residencia en la galería Rua du Sol en Porto (Portugal), invitamos a Edgar Calel, que (según su certificado de nacimiento) nació en 1987 en Comalapa, a presentar algo de su trabajo en Berlín. Cuando digo "invitamos", me refiero a Antje Weitzel, a Çağla Ilk - ambas están a cargo del proyecto y la exposición This might be a place 
for humming birds. (Este pudiese ser un lugar para colibríes) con artistas de/en

Guatemala - y a mí. Pasamos casi dos semanas compartiendo memorias, vivencias, comida, bebida, baile y conocimiento, no sólo con viejxs y nuevxs amigxs dentro de $\mathrm{la}(\mathrm{s})$ esfera(s) del arte, sino también con otras personas migradas de

Latinoamérica, de Centroamérica, de Guatemala. La artista guatemalteca Maya Saravia se vinculó desde el principio a esta micro-residencia de dos semanas como una agente irremplazable; había estudiado con Edgar en la Ciudad de Guatemala y desde hace un tiempo reside en Berlín. Lxs cinco fuimos articulando nuestras visiones y prácticas para hacer posible una charla, que tuvo lugar en el espacio cultural para proyectos uqbar el domingo 8 de septiembre. Esa noche, Edgar y yo navegamos frente al público a través de su obra y por lo tanto, de sus vivencias íntimas y las de sus familiares, amigxs y ancestrxs, así como de la memoria del pueblo Maya-Kaqchiquel. Y es que su obra es la constante traducción de su contexto cotidiano, a la vez sembrado en la historia, a otros, nuevos lenguajes. Nuestras palabras fueron traducidas simultáneamente desde y para el público. Después de hablar, comimos.

\section{Hay un abismo entre el canto y la palabra.}

En $B^{\prime}$ atz - tejido constelación de saberes, Edgar posa de frente y de espaldas, en medio de un campo de maíz, portando un suéter de tela sintética y bordado a mano. La prenda viene de las pacas o tiendas de segunda mano, que revenden ropa que se usó y dejó de usar en los Estados Unidos. Sobre la misma, Edgar bordó los nombres de algunos de los más de veinte grupos Mayas, cada uno con un propio idioma, que habitan en lo que hoy llamamos "Guatemala". Como el maíz, la subjetividad está sembrada en la tierra, por lo tanto, la migración y el desplazamiento equivalen a arrancar una planta de raíz. Lo que ha migrado aquí es el suéter (del norte al sur), que como muchas de estas prendas desechadas se adapta a nuevos cuerpos y contextos (horarios, clima, uso) para los que no fueron concebidas originalmente, reconfigurando los mismos. Pero también se trata de un proceso cotidiano de resignificación desde el cuerpo y la subjetividad Maya. EI tejido de palabras sobre y a través de la prenda agudiza este proceso, inscribiendo idiomas (y saberes) ancestrales que ya difícilmente se pueden destejer. Pero se pueden destejer. La fotografía captura el gesto.

En la práctica artística de Edgar, los objetos migran de un punto a otro en una red de relaciones afectivas, pero también de poder. Los certificados de nacimiento viajan, por ejemplo, en forma de casa de Comalapa (la „periferia", lo „rural") a la capital (el "centro", lo "urbano"), mientras el suéter lo hace desde Estados Unidos (el „norte global") hasta Guatemala (el "sur global"). La presencia del artista en uqbar fue fruto de una migración transatlántica, pero también de sur a norte (en un sentido más figurado que geográfico), del denominado "nuevo" al „viejo" 
continente, de América o Abya Ayala a Europa. Como sujeto artista y como sujeto/cuerpo Maya-Kaqchiquel, Edgar recorrió una ruta histórica, trazada una y otra vez desde que "América" fuera inventada y colonizada, fruto de su "descubrimiento" hace más de 500 años. Según el paradigma del sujeto artista moderno que nos han enseñado, el viaje a Europa es uno de contemplación, escucha y aprendizaje. También lo es de diálogo e intercambio con artistas y agentes culturales (y su fama). iEn cuántas biografías de artistas modernos del sur (casi siempre son los hombres) no figura la amistad con Pablo Picasso u otros "Grandes" durante estadías (hoy quizás diríamos residencias) en París o Nueva York! Los viajes que lleva realizando Edgar desde que comenzó su formación en la Escuela Nacional de Artes Plásticas (ENAP) en la Ciudad de Guatemala se pueden entender, a primera vista, como un eco de la gran travesía del sujeto artista a través del Atlántico, de la "periferia" al "centro", para contemplar, escuchar y aprender el oficio de artista oficialmente. Supongo que la ENAP, como muchas instituciones del arte, está erigida sobre este fundamento ideológico. Comalapa, sin embargo, también es un "centro"; ha sido el hogar de generaciones de pintorxs, escultorxs y músicxs que ejercen en un mercado y circuito de producción, exposición, circulación y discusión artística. Desde hace algunos años y en reacción a nuevas prácticas que entendemos (también a primera vista) como expresiones de arte contemporáneo "global", se empieza a pensar en Comalapa desde esta perspectiva. La visita del último curador general de la Documenta en Kassel (Alemania) Adam Szymczyk es sólo una de las últimas versiones de este movimiento al revés (del norte al sur-centro).

La visita de Edgar a Berlín implicó algunos desvíos en esta ruta, atravesada históricamente por el poder colonial. Uno de ellos fue el hecho de que muchxs de sus interlocutorxs éramos (y seguimos siendo) migrantes por razones diversas, de Turquía, Argentina, Puerto Rico, Brasil y Guatemala (no sólo de la ciudad, sino también de regiones de habla y cultura Mayas). Juntxs, configuramos una comunidad efímera, que no dejaba de ser diversa. Esta unión en la diferencia sólo fue posible gracias a la traducción lingüística y epistémica de vivencias, prácticas y saberes. Esta traducción está llena de errores (productivos) y de opacidad: a veces, no todo lo que se comunica está hecho para traducirse. Juntxs nos entendimos y cada quien entendió algo diferente, ó entendió a través de su diferencia. Esta condición no sólo es inevitable en un encuentro de subjetividades y cuerpos migrantes/migrados diferentes entre sí; es un terreno productivo.

Posterior a su residencia artística Resiliência el año pasado en Silo - Arte e Latitude Rural en Brasil y como parte de un proyecto de película, Edgar realizó una variación de Ixim (Maíz), originalmente el dibujo de una mata de maíz plantada en una carreta para transportar material de construcción. Esta vez, el artista empujó la 
carreta con tierra y maíz a través de las calles de Brasilia en una manifestación indígena (Campamento Tierra Libre) por los derechos de la tierra, es decir, de su tierra; una lucha compartida por muchas comunidades a lo largo y ancho del continente. Durante la acción, contó con la ayuda de Ixs demás manifestantes para cumplir con el trabajo de carga y transporte. Finalmente, plantó el maíz en la planicie frente a los edificios de gobierno, construidos por Oscar Niemeyer como parte del proyecto de centralización y "modernización" de Brasil en los años cincuenta. La carreta de Edgar no transportaba cemento ni material de construcción, como lo hicieron las que empujaron los albañiles de Niemeyer décadas atrás, sino el alimento sagrado para muchos pueblos amerindios y la tierra roja de sus comunidades. El gesto es uno de entrega (de la tierra y a la tierra), pero también de resistencia como forma de protesta y de vida. Esta lucha se agudiza con el régimen de tendencias eco y genocidas de Jair Bolsonaro.

\section{Yin ri in aj tijoy ru xe taj che` - Yo soy el que se come la raiz de los árboles.}

La migración, el desplazamiento y el retorno son sólo algunas de las formas que toma la movilidad y el movimiento en la práctica artística y de vida de Edgar Calel. Como dice él mismo, desde que salió de Comalapa para estudiar arte no ha retornado definitivamente; su vida se ha vuelto un viaje.

Bajo esta premisa, decidimos cocinar enchiladas, tostadas con frijol, guacamol y salsa roja y rellenitos. $Y$ es que los productos, como las personas, también migran en una red de relaciones de poder no poco violentas (siembra y cosecha masiva e industrial, empaque plástico y al vació, transporte, venta y compra, posesión), pero también afectivas (recuerdos de otros tiempos y lugares, una comida compartida hecha por unxs para otrxs). Para las comunidades de migrantes, la preparación y disfrute de recetas caseras se transforma en un ritual de convivencia y memoria compartida desde el aquí y ahora. Juntxs recuerdan y cada quien recuerda algo diferente. Pero las recetas nunca saben igual, por lo menos a mí no. Siempre hay algo que falta o sobra y no me refiero a los ingredientes. Es decir, la memoria (e imaginación) del pasado impide un disfrute completo y entrega al presente inmediato. Esta experiencia pertenece a la condición de migrante, que compartimos desde nuestras diferencias.

Maya, Edgar y yo recorrimos mercados, galeras industriales y pequeñas tiendas de productos de Mesoamérica y de diferentes partes de África y Asia. Compramos tostadas, frijoles, plátanos maduros, hojas de plátano, quesos, maizitos enlatados, perejil, repollo, tomate y demás. Pasamos cocinando toda la noche y el día de la charla, en la que compartimos comida y compartimos comiendo. En esta comunidad efímera de migrantes (y más de alguien nacidx en Berlín), no dejan de haber relaciones de poder. ¿Quién invita y paga la comida, quién la produce, quién 
la cocina, quién la recuerda y quién la come por primera vez, con un hambre de alimentos (y conocimientos) originarios del alguna vez llamado "Nuevo Mundo"?

En 2008, Edgar presentó por primera vez Laberinto de los Pájaros, una serie de pinturas en cajas industriales que encontró en los mercados durante una residencia artística en Managua (Nicaragua). Sobre esta superficie-contenedor de alimentos provenientes de muchos y lejanos lugares, Edgar plasmó las nubes que sólo desde su perspectiva y en su pueblo son visibles. El contexto local, percibido y pintado desde la sensibilidad y el detalle, resignifica las cajas y su interior, permitiendo imaginar otro tipo de migraciones y desplazamientos.

Los alimentos que configuraron nuestra cena aquel domingo fueron transportados en condiciones similares, típicas de la globalización de la inequidad que vivimos y perpetuamos. Las enchiladas y los rellenitos que cenamos esa noche son materia de comercio y posesión, pero también de nostalgia y convivencia migrante. Juntxs y sin querer, embarramos nuestra ropa con los pedacitos de remolacha que se caían de la enchilada al morderla. Ninguna camisa ni pantalón se ensuciaron igual. 